\title{
Absence of Geographic Structure in European Populations of Rubus fruticosus L. Complex Using Chloroplast DNA Microsatellites
}

\author{
Daniela Salvini ${ }^{1}$ and Silvia Fineschi ${ }^{2}$ \\ CNR Istituto per la Protezione delle Piante, I-50019 Sesto Fiorentino - Firenze, Italy \\ Roberta Pastorelli \\ CNR, Istituto di Genetica Vegetale, I-50019 Sesto Fiorentino - Firenze, Italy \\ Federico Sebastiani \\ Dipartimento di Biotecnologie Agrarie, Università degli Studi di Firenze, I-50019 Sesto Fiorentino \\ - Firenze, Italy
}

Giovanni G. Vendramin

CNR, Istituto di Genetica Vegetale, I-50019 Sesto Fiorentino - Firenze, Italy

AdDitional InDEX wORDs. haplotipic diversity, genetic differentiation, simple sequence repeat

\begin{abstract}
Twenty populations of the species aggregate Rubus fruticosus were collected throughout European natural forests and analyzed by chloroplast microsatellites (SSR). Results showed high genetic diversity $\left(h_{\mathrm{T}}=0.73\right)$ and haplotipic richness (17 haplotypes were detected), and the presence of several unique alleles. The value of genetic differentiation between populations was low for unordered alleles $\left(G_{\mathrm{ST}}=0.29\right)$ and for ordered alleles $\left(N_{\mathrm{ST}}=0.30\right)$, revealing the absence of phylogeographic structure of the haplotypic diversity. This can be mainly ascribed to the mechanisms of seed dispersal, mostly mediated by animal ingestion, which are responsible for a efficient gene flow through seeds. Rubus L. species are characterized by the ability to colonizing disturbed, but also intact forest communities, rapidly propagating though suckering and hybridizing with native species. Our results suggest that efficient seed dispersal can counterbalance the effects of vegetative propagation, maintaining a high genetic diversity.
\end{abstract}

Although the genus Rubus (Rosaceae Juss.) has been considered to belong to the subfamily Rosoideae, according to the recent taxonomy (Eriksson et al., 2003), its position is still not securely resolved. The genus comprises a very large number of species bearing complex interrelationships due to frequent interspecific hybridization (Weber, 1996). Flora Europaea (Heslop-Harrison, 1968) describes for this genus five subgenera and more than 2000 species, in Europe: subgenus Chamaemorus (Hill) Focke, subgenus Cyclatis (Rafin.) Focke, subgenus Anoplobatus Focke, subgenus Idaeobatus Focke, and subgenus Rubus L. The genus Rubus has a wide distribution that comprises every continent with the exception of Antarctica.

Rubus species are mostly perennial (in the temperate areas) with a long-lived stem crown and short-lived biennial shoots fruiting in their second year. They are reproductively very versatile, showing both sexual (outcrossing and selfing) and asexual reproduction. This latter includes parthenogenesis, pseudogamy (apomixis requiring pollination), parthenocarpy (production of fruit without fertilization), and vegetative reproduction through suckers or adventitious roots (Gustafsson, 1943, Nybom, 1988). Self-pollination is frequent (Nybom, 1988) and increases the chances of seed production. Rubus species often display high

\footnotetext{
Received for publication 9 Jan. 2006. Accepted for publication 21 June 2006. This study was supported by the European grant FAIR-CT97-3795 Measuring molecular differentiation of European deciduous forests for conservation and management (CYTOFOR).

'Present address: Center for Forest and Landscape, Royal Veterinary and Agricultural University, DK-2970 Hørsholm, Denmark

${ }^{2}$ Corresponding author: CNR Istituto per la Protezione delle Piante, via Madonna del Piano 10, I-50019 Sesto Fiorentino - Firenze, Italy; Tel.: +39 0555225584 e-mail: s.fineschi@ipp.cnr.it
}

polyploidy levels, a factor that minimize inbreeding depression (Amsellem et al., 2000). These adaptations, together with several different modes of propagation, confer to this genus a high capacity to colonize new habitats, as it is typical of invasive species (Barrett and Richardson, 1986). Indeed, Rubus are pioneering plants, their habitat being mainly constituted by open areas bordering forests. They frequently colonize disturbed areas, where the soil is exposed to direct sunlight, like noncultivated fields, lumbered or burnt lands, road edges. There, after seedling establishment, they rapidly spread through vegetative reproduction, mostly by suckering or layering. Seeds are dispersed by birds, some omnivorous mammals (Brunner et al., 1976), and by gravity. Animal dispersal is very relevant and appears to highly increase seed germination, due to activation in the digestive tract (Bruzzese, 1998). Soil seed banks are viable for several years (Brinkman and Kenneth, 1974) allowing germination after disturbance by fire.

Hybridization is common in Rubus: sympatric closely related species are very likely to hybridize, producing fecund progeny (Nybom, 1988). However, hybridizations has also been observed between species belonging to different subgenera (Alice and Campbell, 1999; Alice et al., 2001; Gustafsson, 1943; Spies et al., 1987; Weber, 1996). Therefore, the taxonomy of Rubus has always been a very challenging issue and morphological identification of their species is often a very difficult task, also as a consequence of a high phenotypic plasticity (Nybom and Schaal, 1990).

The study of chloroplast DNA highly variable neutral markers like microsatellites allows us to detect the effects of seed dispersal on the structure of genetic diversity.

The observation that hybridization takes place with high frequency also between distantly related subgenera allows us to study the cpDNA evolution throughout the genus, regardless of 
the species morphological classification, which, in several instances, could be misleading when not wrong. Therefore, Rubus is here seen under the coenospecies concept proposed by Gustafsson (1943), in the sense that interspecific crossings occur so frequently in nature that interspecific borders are extremely faint. As a consequence, we focused our study on the species generally comprised within the name of $R$. fruticosus (subgenus Rubus) seen as an aggregate of a number of closely related species (see the classification proposed by Heslop-Harrison, 1968).

In the case of several tree species, the study of the geographical distribution of cpDNAneutral markers combined with the analysis of pollen data allowed to identify glacial refuges areas and infer postglacial migration routes, especially when combined with palinological data (reviewed by Petit and Vendramin, 2006). No information on fossil pollen is available for the Rosaceae family: the fragility of the pollen grain wall and animal pollination prevents the formation of fossil pollen deposits.

In our study we analyze the pattern of cpDNA variation in 20 European populations of the aggregate species $R$. fruticosus. Chloroplast microsatellites (Weising and Gardner, 1999) were utilized here for measuring the level and distribution of genetic diversity.

\section{Materials and Methods}

Individuals belonging to the genus Rubus were sampled from 20 (Table 1) European deciduous forests. From each site plants were collected within an area of $4 \mathrm{~km}^{2}$. Different individuals were chosen at a distance not less than $50 \mathrm{~m}$, and ideally comprised between 50 and $100 \mathrm{~m}$. Whenever the number of plants within the identified area was not sufficiently large, plants were collected at the immediate peripheral areas. The number of individuals sampled form each population is indicated in Table 1.

For each collected plant, samples were conserved in a herbarium to check the field identification. Leaf samples were frozen in liquid nitrogen and stored at $-80{ }^{\circ} \mathrm{C}$ until DNA extraction.

DNA was extracted from frozen leaves using DNeasy Plant Extraction Kit (Qiagen, Alameda, Calif.) following the manufacturer's instructions.

Chloroplast DNA (cpDNA) microsatellite sequences were selectively amplified via PCR using six specific primer pairs, designed for dicotyledonous angiosperms (Weising and Gardner, 1999): ccmp2, ccmp3, ccmp4, ccmp6, ccmp7, and ccmp10. Amplification reactions and PCR thermal profile are reported in Heuertz et al. (2004). Amplified fragments were separated according to their size differences by means of polyacrylamide gel electrophoresis (Reprogel; Amersham Bioscience, Uppsala, Sweden) in an ALF Express DNA sequencer (Amersham Bioscience).

Different combinations of size variants detected at the different chloroplast regions were considered as haplotypes.

Diversity and differentiation parameters $\left(G_{\mathrm{ST}}\right.$ Nei, 1973) were estimated according to the algorithms described in Pons and Petit (1995, 1996), using the software Permut (Petit, 2006) (for $G_{\mathrm{ST}}$ calculation) and Haplonst (for $N_{\mathrm{ST}}$ calculation and comparison between $G_{\mathrm{ST}}$ and $N_{\mathrm{ST}}$ ).

In addition, spatial analysis of molecular variance [SAMOVA ( $F_{\mathrm{ST}}$ and $\left.R_{\mathrm{ST}}\right)$ ] (Dupanloup et al., 2002) was applied to identify genetic barriers between groups of populations. The program was run for 10,000 iterations for $K \in\{2, \ldots, 13\}$ from each of 500 random initial conditions. For each $K$, the configuration with the largest $F_{\mathrm{CT}}$ values after the 500 independent simulated annealing processes was retained as the best grouping of populations.
Table 1. Description of the 20 Rubus fruticosus complex populations sampled in European forests with indication of their names, their country of origin, geographical coordinates (in decimal degrees), and amplitude of sample size per each population. Forests were chosen to ensure the best possible coverage of western Europe. In most cases, forests of special conservation interest were selected.

\begin{tabular}{|c|c|c|c|c|}
\hline Population & Country & Long. & Lat. & $\begin{array}{c}\text { Samples } \\
\text { size }\end{array}$ \\
\hline $1 \quad$ Glen Affric & & -4.83 & 57.32 & 10 \\
\hline 2 Lake District & United & -3.00 & 54.27 & 10 \\
\hline Dean & Kingdom & -2.65 & 51.83 & 10 \\
\hline 4 Tofta & & 11.93 & 57.60 & 10 \\
\hline Stanshuvud & Sweden & 14.33 & 55.58 & 10 \\
\hline 6 Halltorps Hage & & 18.00 & 56.78 & 6 \\
\hline Kenzingen & & 7.83 & 47.96 & 10 \\
\hline 8 Bovenden & Germany & 10.05 & 51.57 & 10 \\
\hline 9 Echinger Lohe & & 11.83 & 48.93 & 10 \\
\hline 10 Fontainebleau & & 2.67 & 48.42 & 10 \\
\hline 11 Chizé & & -0.40 & 46.14 & 10 \\
\hline 12 Seillon & France & 5.00 & 46.00 & 9 \\
\hline 13 Valbonne & & 4.55 & 44.24 & 3 \\
\hline 14 Devesa da Rogueira & & -7.08 & 42.25 & 10 \\
\hline 15 Valle de Salazar & Spain & -0.92 & 42.83 & 10 \\
\hline 16 Montejo de la Sierra & & -3.50 & 41.13 & 10 \\
\hline 17 Foreste Casentinesi & & 11.80 & 43.78 & 10 \\
\hline 18 Garda Bresciano & Italy & 10.88 & 45.80 & 10 \\
\hline 19 Parco della Sila & & 16.58 & 39.00 & 10 \\
\hline 20 Boki & Slovakia & 19.12 & 48.57 & 9 \\
\hline \multicolumn{5}{|c|}{ Total sample size: 187} \\
\hline
\end{tabular}

An unweighted pair groups method with arithmetic mean (UPGMA) dendrogram was constructed for all haplotypes detected using MEGA3 software (Kumar et al., 2004), taking into account size differences between microsatellite fragments in the distance measure. Distances between haplotypes were calculated using the difference in repeat numbers at each locus (Goldstein et al., 1995a, 1995b).

\section{Results}

Four out of six analyzed chloroplast microsatellite regions (ccmp2, ccmp6, ccmp7, and ccmp10) revealed polymorphism (Table 2). A total of 17 different haplotypes were identified within the sample of 187 individuals representing 20 populations.

Ten haplotypes (H2, H5, H9, H11, H12, H13, H14, H15, H16, H17) were unique to single populations and among them seven haplotypes (H2, H11, H13, H14, H15, H16, H17) appeared only in one individual. Haplotypes H5, H9, and H12 turned out to be private for English population 2 (Lake District), Swedish population 4 (Tofta), and Spanish populations 14 (Devesa da Rogueira), respectively (Fig. 1).

Haplotype 1 was the most frequent (almost 50\%), and is present in all populations but two (German Bovenden and Slovakian Boki) (Table 3). Furthermore, haplotype 1 is fixed in two populations (Swedish Stanshuvud and Spanish Montejo de la Sierra). Interestingly, German population Bovenden is the most polymorphic one, with seven different haplotypes, five of which are unique ones. In contrast to this result, the other two German populations (Kenzingen and Echinger Lohe) are mostly represented by haplotype 1. Haplotypes H4 (Scottish population 1 and Slovakian population 20) and H10 (German populations 7 and 8) appeared only in two populations and at very low frequency. 
Table 2. Description of 17 microsatellite haplotypes identified in the European Rubusfruticosus complex populations. The second column indicates the distribution of each haplotype among the populations. Per each haplotypes the size of the four polymorphic microsatellites (ccmp2, ccmp6, ccmp7, and ccmp10) is indicated in base pair.

\begin{tabular}{llllll}
\hline Haplotype & \multicolumn{1}{c}{ Populations } & ccmp2 & ccmp6 & ccmp7 & ccmp10 \\
\hline H1 & $1,2,3,4,5,6,7,9,10,11$, & & & & \\
& $12,13,14,15,16,17,18,19$ & 238 & 108 & 135 & 105 \\
H2 & 1 & 248 & 107 & 135 & 108 \\
H3 & $1,2,3,10,11,13,17,18,19$ & 238 & 108 & 135 & 113 \\
H4 & 1,20 & 238 & 107 & 135 & 108 \\
H5 & 2 & 230 & 107 & 135 & 105 \\
H6 & $1,6,10,17,20$ & 238 & 108 & 135 & 108 \\
H7 & $2,8,9,12,14,20$ & 238 & 107 & 135 & 105 \\
H8 & $3,4,12,15,20$ & 250 & 108 & 135 & 108 \\
H9 & 4 & 237 & 106 & 135 & 105 \\
H10 & 7,8 & 267 & 108 & 135 & 108 \\
H11 & 9 & 267 & 108 & 135 & 105 \\
H12 & 14 & 238 & 109 & 135 & 105 \\
H13 & 8 & 238 & 107 & 138 & 105 \\
H14 & 8 & 238 & 107 & 140 & 105 \\
H15 & 8 & 250 & 108 & 137 & 108 \\
H16 & 8 & 250 & 108 & 139 & 108 \\
H17 & 8 & 267 & 108 & 136 & 108 \\
\hline
\end{tabular}

Among the haplotypes that cluster together (i.e., are closely related) in the UPGMA dendrogram (Fig. 2) with bootstrap consensus, four pairs of haplotypes and a group of three haplotypes have a well-defined geographical structure because they occur either within the same population or in the close vicinity. Therefore, 11 haplotypes out of $17(60 \%)$ show a clearly defined geographical structure. In particular, haplotypes 4 and 6 (related with $99 \%$ consensus) are co-occurring in populations 20 from
Slovakia and one from Scotland. Haplotypes 1 and 12 (related with $52 \%$ consensus) co-occur only in the Spanish population 14. Clusters of haplotypes 13-14, 15-16, and 10-17 (related with $94 \%, 56 \%$, and $99 \%$ consensus, respectively) co-occur in the same population 8 (Bovenden). If we consider the cluster formed by haplotypes 10,11 , and 17 (related with $100 \%$ consensus) we find out that they only occur in the same central European area formed by populations 7,8 , and 9 (Germany). The most unique and rare haplotypes are found in central and northern Europe.

The most diverse Rubus population appears to be the German population 8 (Bovenden), with seven different haplotypes for only 10 individuals, six of which being represented by only one individual, and all unique to this population except of $\mathrm{H} 10$, which also appears in the contiguous population 7 (Kenzingen).

Genetic parameters revealed high value of total genetic diversity $\left(h_{\mathrm{T}}=0.73\right)$ (Table 4$)$ but relatively low level of genetic differentiation $\left(G_{\mathrm{ST}}=0.29\right)$ compared to what observed for other broadleaved species using maternally inherited markers (Petit et al., 2003). The difference between the coefficient of genetic differentiation for nonordered alleles $\left(G_{\mathrm{ST}}\right)$ and ordered alleles $\left(N_{\mathrm{ST}}\right.$ $=0.30)$ was nonsignificant $(P>0.05)$, thus revealing the absence of a phylogeographic structure (Pons and Petit, 1996).

The SAMOVA algorithm did not allow us to unambiguously identify the number $K$ of groups of populations displaying the highest differentiation among groups, $F_{\mathrm{ST}}$. This was because $F_{\mathrm{ST}}$ values increased progressively as $K$ was increased, reaching a plateau at $K \approx 7$ (SAMOVA $F_{\mathrm{ST}}$ ). SAMOVA confirmed the lack of a significant geographic structure. Nevertheless there is a tendency of grouping populations from northern Italy and southern Germany (group 7), as well as some populations from central Europe (group 1) characterized by high haplotypic diversity (Fig. 3).

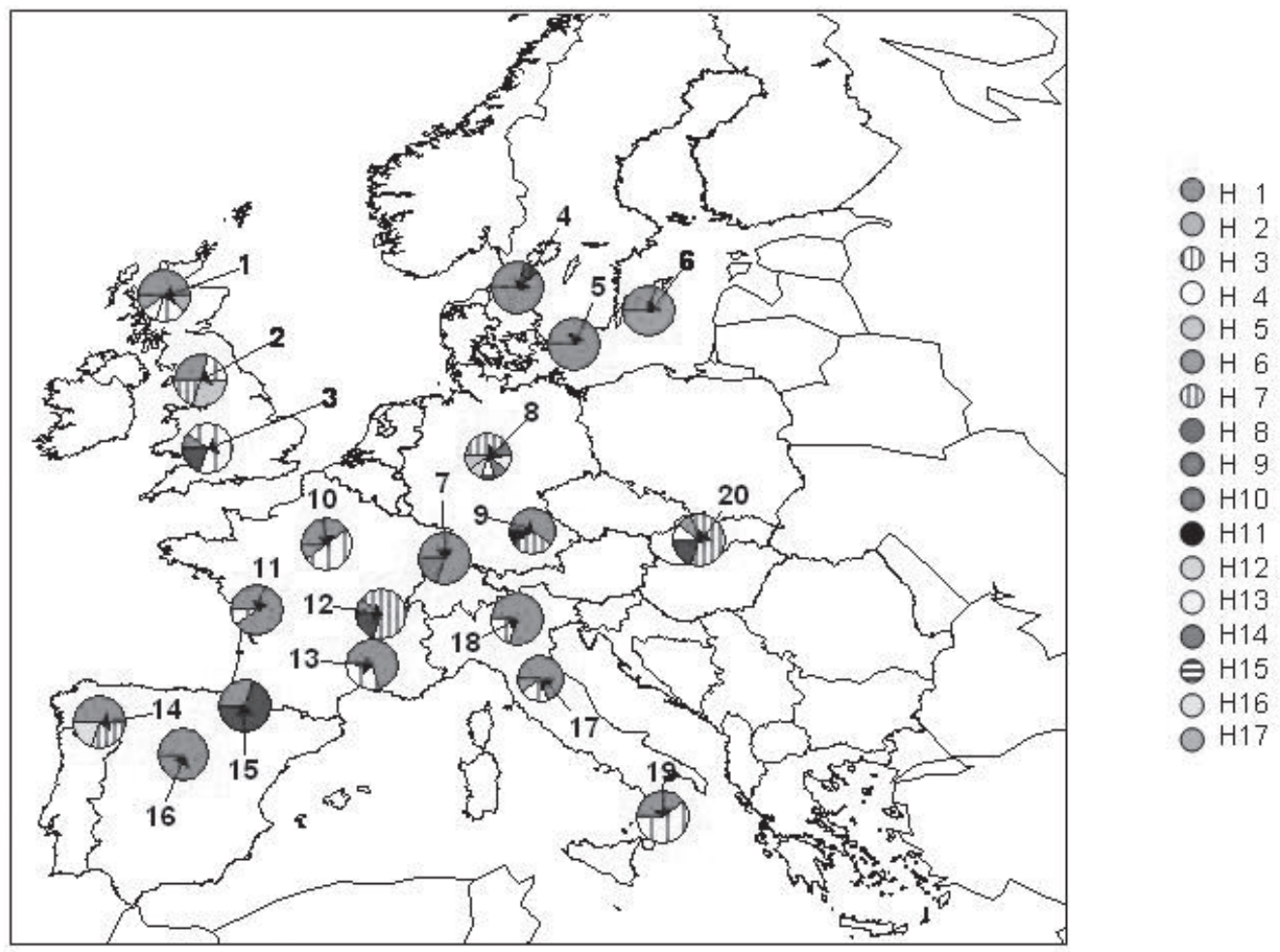

Fig. 1. Distribution of cpDNA haplotypes within Rubus populations. Populations are numbered according to Table 1. Haplotype numbers (H1 to H17) are defined according to length variants as indicated in Table 2 and their distribution among populations is given in Table 3 . 


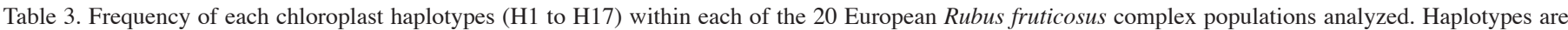
defined combining the size variants detected at the different chloroplast regions. Last row indicates the average frequency over all populations.

\begin{tabular}{|c|c|c|c|c|c|c|c|c|c|c|c|c|c|c|c|c|c|c|}
\hline \multirow[b]{2}{*}{$\begin{array}{l}\text { Population } \\
\text { no. }\end{array}$} & \multicolumn{18}{|c|}{ Haplotype } \\
\hline & $\mathrm{H} 1$ & $\mathrm{H} 2$ & H3 & $\mathrm{H} 4$ & H5 & H6 & $\mathrm{H} 7$ & H8 & H9 & H10 & H11 & H12 & H13 & H14 & H15 & H16 & H17 & $\begin{array}{c}\text { Individuals } \\
\text { (no.) }\end{array}$ \\
\hline 1 & 0.5 & 0.1 & 0.2 & 0.1 & - & 0.1 & - & - & - & - & - & - & - & - & - & - & - & 10 \\
\hline 2 & 0.3 & - & 0.2 & - & 0.3 & - & 0.2 & - & - & - & - & - & - & - & - & - & - & 10 \\
\hline 3 & 0.1 & - & 0.7 & - & - & - & - & 0.2 & - & - & - & - & - & - & - & - & - & 10 \\
\hline 4 & 0.3 & - & - & - & - & - & - & 0.1 & 0.6 & - & - & - & - & - & - & - & - & 10 \\
\hline 5 & 1.0 & - & - & - & - & - & - & - & - & - & - & - & - & - & - & - & - & 10 \\
\hline 6 & 0.3 & - & - & - & - & 0.7 & - & - & - & - & - & - & - & - & - & - & - & 6 \\
\hline 7 & 0.8 & - & - & - & - & - & - & - & - & 0.2 & - & - & - & - & - & - & - & 10 \\
\hline 8 & - & - & - & - & - & - & 0.4 & - & - & 0.1 & - & - & 0.1 & 0.1 & 0.1 & 0.1 & 0.1 & 10 \\
\hline 9 & 0.6 & - & - & - & - & - & 0.3 & - & - & - & 0.1 & - & - & - & - & - & - & 10 \\
\hline 10 & 0.4 & - & 0.5 & - & - & 0.1 & - & - & - & - & - & - & - & - & - & - & - & 10 \\
\hline 11 & 0.9 & - & 0.1 & - & - & - & - & - & - & - & - & - & - & - & - & - & - & 10 \\
\hline 12 & 0.1 & - & - & - & - & - & 0.7 & 0.2 & - & - & - & - & - & - & - & - & - & 9 \\
\hline 13 & 0.7 & - & 0.3 & - & - & - & - & - & - & - & - & - & - & - & - & - & - & 3 \\
\hline 14 & 0.5 & - & - & - & - & - & 0.3 & - & - & - & - & 0.2 & - & - & - & - & - & 10 \\
\hline 15 & 0.3 & - & - & - & - & - & - & 0.7 & - & - & - & - & - & - & - & - & - & 10 \\
\hline 16 & 1.0 & - & - & - & - & - & - & - & - & - & - & - & - & - & - & - & - & 10 \\
\hline 17 & 0.7 & - & 0.2 & - & - & 0.1 & - & - & - & - & - & - & - & - & - & - & - & 10 \\
\hline 18 & 0.8 & - & 0.2 & - & - & - & - & - & - & - & - & - & - & - & - & - & - & 10 \\
\hline 19 & 0.4 & - & 0.6 & - & - & - & - & - & - & - & - & - & - & - & - & - & - & 10 \\
\hline 20 & - & - & - & 0.1 & - & 0.1 & 0.6 & 0.2 & - & - & - & - & - & - & - & - & - & 9 \\
\hline & & & & & & & & & & & & & & & Tot & sampl & size & 187 \\
\hline Frequency & 0.485 & 0.005 & 0.150 & 0.010 & 0.015 & 0.055 & 0.125 & 0.070 & 0.030 & 0.015 & 0.005 & 0.010 & 0.005 & 0.005 & 0.005 & 0.005 & 0.005 & 1.000 \\
\hline
\end{tabular}

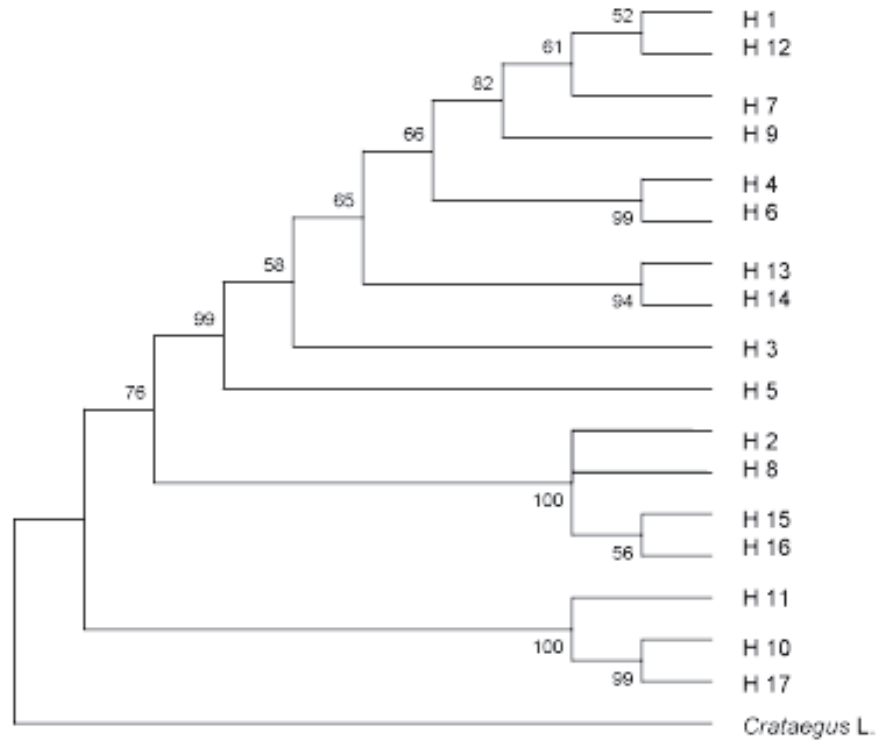

Fig. 2. UPGMAdendrogram obtained using Goldstein et al. (1995a, 1995b) genetic distance matrix with bootstrap consensus for all haplotypes detected in Rubus fruticosus complex using MEGA3 software (Kumar et al., 2004). Four pairs of haplotypes have a well-defined geographical structure because they occur either within the same population or in the close vicinity: H4-H6 (related with 99\% consensus); H1-H12 (related with 52\% consensus); H13-H14 (related with 94\%); and H15-H16 (related with 56\% consensus). Haplotypes 10, 11, and 17 occur in the same central European area (German populations) and form one cluster (related with $100 \%$ consensus). Crataegus represents the outgroup.

\section{Discussion}

Results obtained on Rubus demonstrated that this species is characterized by a high level of polymorphism in terms of haplotype number. The great majority of haplotypes is unique or rare: together with a widespread haplotype (H1), which occurs in 18 out of the 20 sampled populations and has an overall frequency of
Table 4. Parameters of haplotypic diversity $\left(h_{\mathrm{T}}\right)$, total genetic diversity $\left(v_{\mathrm{T}}\right)$, average genetic diversity within populations $\left(h_{\mathrm{S}}, v_{\mathrm{S}}\right)$, genetic differentiation for unordered alleles $\left(G_{\mathrm{ST}}\right)$, and genetic differentiation for ordered alleles $\left(N_{\mathrm{ST}}\right)$ calculated for European Rubus fruticosus complex populations.

\begin{tabular}{lcc}
\hline Parameter $^{2}$ & Value & SE \\
\hline$h_{\mathrm{S}}$ & 0.518 & 0.053 \\
$h_{\mathrm{T}}$ & 0.730 & 0.058 \\
$G_{\mathrm{ST}}$ & 0.291 & 0.049 \\
$v_{\mathrm{S}}$ & 0.134 & 0.021 \\
$v_{\mathrm{T}}$ & 0.191 & 0.027 \\
$N_{\mathrm{ST}}$ & 0.302 & 0.036 \\
\hline
\end{tabular}

Pons and Petit, 1995, 1996.

$\approx 50 \%, 10$ haplotypes out of 17 are unique for single populations. A relatively low genetic differentiation and the absence of phylogeographic structure were observed in this species. The absence of geographic structure was revealed by SAMOVA analysis using the number of pairwise differences as a distance measure. The highest $F_{\mathrm{ST}}$ value (0.34) obtained corresponds to seven groupings of populations (Fig. 3), among which five populations showing the highest number of haplotypes compose two groups.

The low genetic differentiation is shown by the low $G_{\mathrm{ST}}$, which has an overall value of $0.291(\mathrm{SE}=0.049)$ and is placed within the range detected so far in Rosaceae species $(0.24$ for Crataegus monogyna Jacq., 0.29 for Prunus avium L., 0.32 for P. spinosa L., 0.33 for Sorbus torminalis L., Petit et al., 2003), all characterized by animal ingested seed dispersal. This result can be explained by the predominant mode of dissemination relying on animal vectors. Indeed, fleshy fruit of Rosaceae are usually ingested by animals (birds and small mammals), which provide a very efficient dissemination mechanism. Birds in particular could act as long distance seed dispersers of Rubus. High (genetic differentiation values $G_{\mathrm{ST}}=0.84$ ) were detected in Quercus L. 


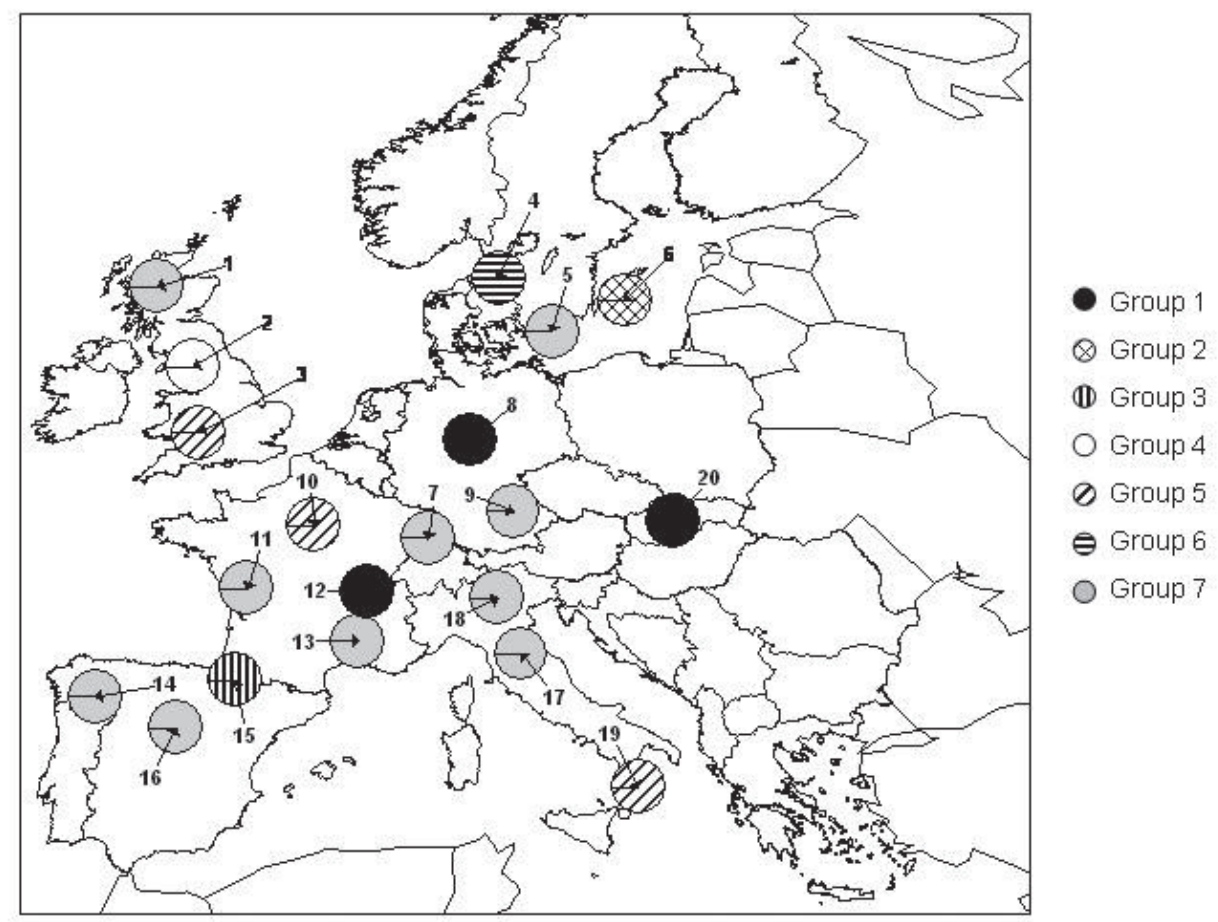

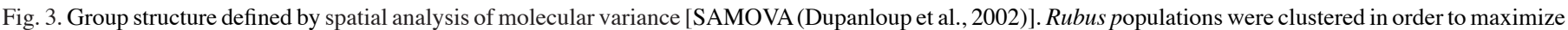

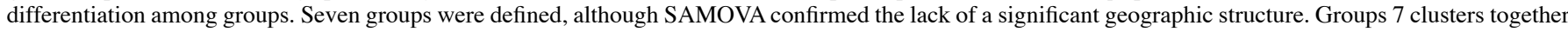

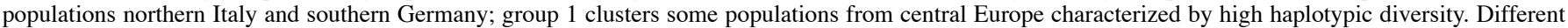
colours (and/or patterns) indicate the seven groups of populations.

(section Robur L.), whose seeds are mainly dispersed by gravity (Petit et al., 2003).

The absence of a phylogeographic structure is revealed by the fact that $N_{\mathrm{ST}}$ is not significantly different from $G_{\mathrm{ST}}$ (Pons and Petit, 1996), as a result of the co-occurrence of haplotypes of different origins, which seems to confirm and emphasize the importance of seed dispersal due to bird feeding habit.

Several studies dealing with Rosaceae and other species characterized by a bird mediated seed dispersal (but see Grivet and Petit, 2002; Hampe et al., 2003) demonstrated the lack of a phylogeographic structure, which was also attributed to the limited sampling of populations in the southernmost distribution range (Hampe et al., 2003). However, this hypothesis can be rejected for Rubus, considering that a relatively high number of populations was sampled in the Italian and Iberian peninsulas and also by the simple observation of the haplotype distribution across the wide sampling range. Perhaps a more localized and dense sampling could elucidate the importance of animal seed dispersal in relation to vegetative propagation. Our observations clearly show that vegetative reproduction proceeds at a considerably slower pace compared to seed migration rate in Rubus and that both mechanisms could interact and complement one another. While vegetative propagation could help short distance habitat colonization, efficient seed dispersal can counterbalance the deleterious effects of the clonal regeneration, maintaining a high genetic diversity. A significant seed flow mediated by birds may indeed occur also among very distant, already established populations. The presence of a widespread haplotype distributed exclusively along a northwest-southeast gradient (e.g., H3, detected in Great Britain, France, and the Italian peninsula) could be related to bird migration routes, the importance of which has already been emphasized for Frangula alnus Mill. by Hampe et al. (2003).
A correlation can often be detected between genetic distance and geographical distance, especially in plants, where migration corresponds to seed dispersal and when maternally inherited neutral cytoplasmic markers are used. Neutral markers, though subject to homoplasy, will tend to diverge through random mutation events, since they are not under selective pressure. In such case haplotypes evolved in different areas converge into the same forest due to the confluence of migration routes of postglacial recolonization. Indeed, it has been observed that the co-occurrence of very divergent haplotypes may indicate the past confluence of recolonization routes, leading to admixtures of divergent evolutionary lineages (Petit et al., 2003). Closely related haplotypes occurring within the same population may indicate the presence of a diversity hotspot. The central European area is indeed likely to be a crossroad of recolonization routes for species having their refuges placed in Iberian, Italian and Greek peninsulas (Petit et al., 2003). Unfortunately, no fossil pollen data are available for Rubus to infer potential refugium, because of the characteristic alterability of pollen of the Rosaceae family. The only indication is given by Gustafsson (1943), who postulates a central European origin for the Rubus genus, on the basis of the species richness of these regions.

Although it is difficult to identify refuges based only on genetic data, our results also indicate a high intraspecific diversity in central European populations. In particular, the largest part of unique and rare haplotypes is placed in central and northern Europe. The most diverse Rubus population appears to be population 8 (Bovenden, Germany), with seven different haplotypes, five of which are unique to this population. It is interesting to observe that these unique haplotypes are related to each other, forming three clusters of haplotypes (H13 with $\mathrm{H} 14, \mathrm{H} 15$ with $\mathrm{H} 16$, and $\mathrm{H} 10$ with H17, Fig. 2). This is a condition typical of a "diversity hotspot" rather than "melting pot" (see Petit et al., 2003). Rubus 
populations from Iberian and Italian peninsulas, which are two of the main refuges for most temperate European broadleaved species (Petit et al., 2003), display low haplotypic diversity. Their low genetic diversity is probably the result of a relatively recent colonization, producing founder effects.

In conclusion, Rubus is an important component of wild areas because of its ecological significance (food for wildlife). The dynamics of its diffusion is dependent on its habitat colonization ability, which is associated to both animal seed dispersal at long distances and vegetative propagation at shorter distances, and make Rubus particularly suited to colonizing areas subject to drastic changes in site conditions (Olmsted and Curtis, 1947), but also able in invading intact forest communities (Randell et al., 2004) without losing genetic diversity. Our results seem to confirm the high efficiency of animal mediated seed flow, considering the low level of differentiation and the absence of geographic structure detected in the European Rubus populations. An efficient long distance seed flow is an important factor favoring colonization of new areas where native species are growing and where hybridization can occur. The high colonization ability (i.e., by seeds) displayed by Rubus is also reflected in its wide distribution in Europe and other continents.

\section{Literature}

Alice, L.A. and C.S. Campbell. 1999. Phylogeny of Rubus (Rosaceae) based on nuclear ribosomal DNA internal transcribed spacer region sequences. Amer. J. Bot. 86:81-97.

Alice, L.A. 2001. Hybridization and gene flow between distantly related species of Rubus (Rosaceae): Evidence from nuclear ribosomal DNA internal transribed spacer region sequences Syst. Bot. 26:769-778.

Amsellem, L., J.L. Noyer, T. Le Bourgeois, and M. Hossaert-McKey. 2000. Comparison of genetic diversity of the invasive weed Rubus alceifolius Poir. (Rosaceae) in its native range and in areas of introduction, using amplified fragment length polymorphism (AFLP) markers. Mol. Ecol. 9:443-455.

Barrett, S.C. and H.B.J. Richardson. 1986. Genetic attributes of invading species, p. 254-277. In: A.H.D. Brown, M.T. Clegg, A.L. Kahler, and B.S. Weir (eds.). Plant population genetics, breeding and genetic resources. Sinauer, Sunderland, Mass.

Brinkman, K.A. and A. Kenneth. 1974. Rubus L., blackberry, raspberry, p. 738-743. In: C.S. Schopmeyer (ed.). Seeds of woody plants in the United States. Agr. Hdbk. No. 450. U.S. Dept. of Agr., For. Ser., Washington, D.C.

Brunner, H., R.V. Harris, and R.L. Amor. 1976. A note on the dispersal of seeds of blackberry (Rubus procerus P.J. Muell.) by foxes and emus. Weed Res. 16:171-173.

Bruzzese, E. 1998. The biology of blackberry in south-eastern Australia. Plant Protection Quarterly 13:160-162.

Dupanloup, I., S. Schneider, and L. Excoffier. 2002. A simulated approach to define the genetic structure of populations. Mol. Ecol. 11:2571-2581.

Eriksson, T., M.S. Hibbs, A.D. Yoder, C.F. Delwiche, and M.J. Donoghue. 2003. The phylogeny of Rosoideae (Rosaceae) based on sequences of internal transcribed spacers (ITS) of nuclear ribosomal DNA and the $\operatorname{trn} L / F$ region of chloroplast DNA. Intl. J. Plant Sci. 164:197-211.

Goldstein, D.B., A.R. Linares, L.L. Cavalli-Sforza, and M.W. Feldman. 1995a. An evaluation of genetic distances for use with microsatellite loci. Genetics 139:463-471.
Goldstein, D.B.,A.R. Linares, L.L. Cavalli-Sforza, and M.W. Feldman. 1995b. Microsatellite loci, genetic distances and human evolution. Proc. Natl. Acad. Sci. USA 92:6723-6727.

Grivet, D. and R.J. Petit. 2002. Phylogeography of the common ivy (Hedera sp.) in Europe: Genetic differentiation through space and time. Mol. Ecol. 11:1351-1362.

Gustafsson, A. 1943. The genesis of the European blackberry flora. Acta Universistet Lundskrift 39:1-200.

Hampe, A., J. Arroyo, P. Jordano, and R.J. Petit. 2003. Rangewide phylogeography of a bird-dispersed Eurasian shrub: Contrasting Mediterranean and temperate glacial refuges. Mol. Ecol. 12:3415-3426.

Heslop-Harrison, Y. 1968. Rubus, p. 7-25. In: T.G. Tutin, V.H. Heywood, N.A. Burges, D.H. Valentine, S.M. Walters, and D.A. Webb (eds.). Flora Europaea Cambridge, Vol. 2. Cambridge University Press, Cambridge, U.K.

Heuertz, M., S. Fineschi, M. Anzidei, R. Pastorelli, D. Salvini, L. Paule, N. Frascaria-Lacoste, O.J. Hardy, X. Vekemans, and G.G. Vendramin. 2004. Chloroplast DNA variation and postglacial recolonization of common ash (Fraxinus excelsior L.) in Europe. Mol. Ecol. 13:3437-3452.

Kumar, S., K. Tamura, and M. Nei. 2004. MEGA3: Integrated software for molecular evolutionary genetics analysis and sequence alignment. Briefings Biomathematics 5:150-163.

Nei, M. 1973. Analysis of gene diversity in subdivided populations. Proc. Natl. Acad. Sci. USA 70:3321-3323.

Nybom, H. 1988. Apomixis versus sexuality in blackberries (Rubus subgen. Rubus, Rosaceae). Plant Systematics Evol. 160:207-218.

Nybom, H. and B.A. Schaal. 1990. DNA fingerprints reveal genotypic distributions in natural populations of blackberries and raspberries (Rubus, Rosaceae). Amer. J. Bot. 77:883-888.

Olmsted, N. and J. Curtis. 1947. Seeds of the forest floor. Ecology 28:49-52.

Petit, R.J., I. Aguinagalde, J.L. de Beaulieu, C. Bittkau, S. Brewer, R. Cheddadi, R. Ennos, S. Fineschi, D. Grivet, M. Lascoux, A. Mohanty, G. Müller-Starck, B. Demesure-Musch, A. Palmé, J.P. Martín, S. Rendell, and G.G. Vendramin. 2003. Glacial refugia: Hotspots but not melting pots of genetic diversity. Science 300:1563-1565.

Petit, R.J. 2006. PERMUT. UMR 1202 - BIOGECO - Genetics. 4 Apr. 2006. <http://www.pierroton.inra.fr/genetics/labo/Software/PermutCpSSR/index.html>.

Petit, R.J. and G.G. Vendramin. 2006. Plant phylogeography based on organelle genes: An introduction. In: S. Weiss, and N. Ferrand (eds.). Phylogeography of southern European refugia. Kluwer, Amsterdam, The Netherlands. (In press).

Pons, O. and R.J. Petit. 1995. Estimation, variance and optimal sampling of gene diversity. I. Haploid locus. Theor. Appl. Genet., 90:462-470.

Pons, O. and R.J. Petit. 1996. Measuring and testing genetic differentiation with ordered versus unordered alleles. Genetics 144:1237-1245.

Randell, R.A., D.G. Howarth, and C.W. Morden. 2004. Genetic analysis of natural hybrids between endemic and alien Rubus (Rosaceae) species in Hawaii. Conservation Genet. 5:217-230.

Spies, J.J., C.H. Sirtin, and H. Du Plessis. 1987. The genus Rubus (Rosaceae) in South Africa. IV Natural hybridisation. Bothalia 17:105-119.

Weber, H.E. 1996. Former and modern taxonomic treatment of the apomictic Rubus complex. Folia Geobotanica Phytotaxonomica 31:373-380.

Weising, K. and R.C. Gardner. 1999. A set of conserved PCR primers for the analysis of simple sequence repeat polymorphisms in chloroplast genomes of dicotyledonous angiosperms. Genome 42:9-19. 